\title{
Acorde estrangeiro: representação e confrontos linguísticos na música brasileira
}

Marly D'Amaro Blasques Tooge*

(...) a música popular brasileira é a mais completa, mais totalmente nacional, mais forte criação de nossa raça até agora.

Mário de Andrade

Abstract: This paper is a study on contemporary "Brazilian cultural representation" through texts produced in the scope of Brazilian music. Such texts, in the format of songs, build a corpus which can reveal different usages of languages, in order to articulate the relation with "the foreign other". Such artistic manifestation has been, for a long time, the stage for debates and discussion on national identity. Ideological clashes and identity projects have produced different uses of languages, which revealed not only trends of harsh nationalism, but also those of consent to foreign influence, something that can be easily demonstrated in the aforementioned corpus. As an instrument of language and culture dissemination, music shows how artists manipulated the languages, creating "strategies of linguistic confrontation", in order to make survive element of the so called "Brazilian Culture".

Keywords: translation; representation; transculturation; Brazilian music; identity.

Resumo: Neste trabalho, buscou-se estudar a "representação cultural brasileira" na contemporaneidade, através dos textos produzidos dentro do contexto da música brasileira. Acreditamos que tais textos, no formato de canções, montam um corpus de estudo que pode revelar diferentes usos das línguas para articular a relação com 0 "outro estrangeiro". Tal atividade artística tem sido, há tempos, palco de discussões e negociações sobre a identidade nacional. Tensões ideológicas e projetos identitários produziram usos variados dos idiomas, refletindo tanto correntes de

\footnotetext{
* Doutoranda da área de Estudos Linguísticos e Literários em Inglês. Email: marlytooge@terra.com.br.
} 
nacionalismo acirrado, quanto de abertura à influência estrangeira, movimentos que podem ser claramente verificados nesse corpus. Como instrumento de difusão de língua e cultura, a música revela usos de idiomas e "estratégias de confronto linguístico", na busca da sobrevivência de elementos da "cultura brasileira".

Palavras-chave: tradução; representação; transculturação; música brasileira; identidade. 
Tooge, M. D. B. - Acorde estrangeiro: representação e confrontos linguísticos na música brasileira

\section{Introdução}

O título deste artigo, que reproduz aquele da tese de doutorado do autor deste trabalho, tem propositalmente um sentido múltiplo: "acorde" tanto representa a escrita ou a execução simultânea de notas musicais, quanto a forma imperativa do verbo "acordar" na terceira pessoa do singular. Esta, por sua vez, é utilizada para a conjugação do pronome "você" - tipicamente utilizado em várias regiões do Brasil, mas não em Portugal. 0 verbo "acordar", todavia, também tem dupla significação: pode referir-se a "despertar", "tomar consciência de algo", ou a "entrar em acordo". Dessa forma, a expressão "acorde estrangeiro" faz alusão tanto ao som produzido pelo estrangeiro, aquele que nos é "estranho" ou "exótico", quanto a uma ordem para que o estrangeiro ganhe consciência do que está ocorrendo, ou, ainda, de que ele "entre em acordo" - aquele da "negociação" existente em todo o trâmite de "representação do outro". Essa complexa multiplicidade de sentidos nos parece adequada para falar da representação da(s) cultura(s) brasileira(s) através da música, no ambiente internacional. A ideia de tal título teve como inspiração, a princípio, o nome do disco do compositor Caetano Veloso gravado em 2004: A Foreing Sound. Nele existe, em nossa opinião, ao mesmo tempo uma ideia de "estranheza" causada pela sonoridade e pela "voz" de uma cultura estrangeira e proposta de atração do compositor por esse mesmo ritmo e essa mesma cultura. Já nosso "acorde estrangeiro" amplia essa dualidade e propõe que "despertar" para os sons, as vozes do estrangeiro, é também conscientizar-se de sua riqueza cultural. A escolha do termo "enfrentamentos" se deu não em função da alusão a disputas, mas sim à ideia de colocar "frente a frente" os idiomas.

Este artigo filia-se à área dos Estudos da Tradução, campo de estudo que tem expandido nas últimas décadas, graças a propostas como as da professora da Universidade de Massachusetts, Maria Tymoczko, para quem o campo de 
Tooge, M. D. B. - Acorde estrangeiro: representação e confrontos linguísticos na música brasileira

estudos deve abrir-se a uma maior diversidade de textos e expandir seu objeto de trabalho (TYmoczko 2003: 17-19). Tymoczko também defende a exploração de novos modos de interface cultural, entre eles a "representação" (a construção e a exibição de imagens, reconhecendo a necessidade de pensar os aspectos ideológicos envolvidos nesse processo) e a "transculturação" (a transmissão de características culturais de um grupo cultural a outro, indo além da transferência de materiais verbais, e incluindo a transferência de ideias sobre religião, governo, divulgação de formas artísticas e materiais de mídia [TYMoczko 2003: 21-24]). Faz parte, ainda, das propostas da autora inserir no campo de estudos a sondagem dos processos envolvidos na "tradução" de formas artísticas, como a música e as artes visuais (TYMoczko 2003: 23). É com base em tais propostas que buscou-se estudar os processos de transculturação e de representação dentro do âmbito da música brasileira.

Para isso, foi levantado um corpus de estudo composto por letras de canções elaboradas desde o início do século XX no Brasil. O período não foi escolhido aleatoriamente, mas por ser um período de grandes modificações ou transições políticas e sociais no Brasil: no princípio do século, escravos libertos haviam migrado para o Rio de Janeiro (SEVCENKO 2003: 41), enfrentando mais tarde as políticas sanitaristas da Velha República (SANTOS 1985: 194); o governo ainda dava continuidade à "americanização da política externa brasileira" iniciada por Rio Branco (Bethell 2009); aumentava o processo de imigração e de industrialização no Brasil, enquanto diferentes grupos de intelectuais buscavam redefinir a ideia de nação brasileira.

Em meio a toda a efervescência da época, acontecia a primeira transmissão de rádio no Brasil, no Rio de J aneiro, inaugurando as transmissões na segunda década do século XX. O primeiro grande veículo de comunicação do século logo veria nascer a "Era de Ouro do Rádio", a consagração de um instrumento que trouxe, entre outras coisas, a música para dentro das casas dos brasileiros. 
Tooge, M. D. B. - Acorde estrangeiro: representação e confrontos linguísticos na música brasileira

A partir daí, um processo crescente de reformulação identitária passaria a ser associado à música. Nas palavras de Michell Nicolau Netto:

(...) a música popular desde o começo do século XX foi tratada - a partir de uma série de processos de ressignificação, como procuraremos mostrar - como um símbolo identitário nacional privilegiado, um símbolo que passou a ser discursado sob o registro da brasilidade, daquilo que nos propõe uma forma enquanto povo. Ainda, é a indústria da música popular a mais impactada pelos avanços tecnológicos em termos de circulação. Por ser de produção muito mais simples do que um filme ou um programa de TV e por se adaptar com mais competência ao ímpeto individualista da sociedade contemporânea, ela é mais competente em se relacionar com os novos meios de comunicação para se espalhar sobre as fronteiras. No caso da música popular brasileira, então, ao fazer isso ela leva consigo a identidade nacional para um espaço global e, com isso, seu estudo permitirá entender como esta identidade passa a ser articulada a partir de seu deslocamento (Nicolau NetTo 2009: 17).

Mas, o processo de transmissão dos elementos das camadas populares para o centro do sistema musical brasileiro como símbolo nacional não foi nada simples. José Ramos Tinhorão explica, em seu ensaio Música Popular um tema em debate (TINHORÃo 1967: 17-21), como "Os gêneros da música urbana reconhecidos como tipicamente cariocas - o samba e a marcha surgiram e se fixaram no período de 60 anos que vai de $1870(\ldots)$ até 1930 (...)". O samba, juntamente com a marcha, como "criação consciente, destinada a atender a fins específicos: a necessidade de ritmos capazes de servirem à cadência das lentas passeatas dos ranchos (...) e à procissão desvairada dos blocos e cordões carnavalescos" (TINHORÃo 1967: 17) resultaria, na década de 1930, já "amansado" para "o gosto das novas camadas da classe média", com uma série de variações em torno do ritmo fundamental de 2/4. Diz Tinhorão:

A história do samba carioca é, assim, a história da ascensão social contínua de um gênero de música popular urbana, num fenômeno em tudo semelhante ao do jazz, nos Estados Unidos. Fixado como gênero musical por compositores de camadas baixas da cidade, a partir de motivos ainda cultivados no fim do século XIX por negros oriundos da zona rural, o samba criado à base de instrumentos de percussão passou 
Tooge, M. D. B. - Acorde estrangeiro: representação e confrontos linguísticos na música brasileira

ao domínio da classe média, que o vestiu com orquestrações logo estereotipadas, e o lançou comercialmente como música de dança de salão (TINHORÃO 1967: 18).

Dessa forma, para Tinhorão, o samba seria o resultado da apropriação de ritmos populares pelas classes mais altas. Ana Maria Rodrigues parece ter uma opinião similar, defendendo que a criação da ideia de democracia racial brasileira, para ela uma estratégia de branqueamento, tivesse sido uma forma de enfraquecer o caráter étnico das "associações carnavalescas dos negros" e impedindo que surgisse uma "consciência negra" (NAPOLITANO \& WASSERMAN 2000: 181). Muniz Sodré vê o samba "como um movimento de continuidade e afirmação dos valores culturais negros, uma cultura não oficial e alternativa, que seria uma forma de resistência cultural ao modo de produção dominante da sociedade carioca do início do século XX" (idem). Enquanto isso, Hermano Vianna enfatiza o panorama cultural das primeiras décadas do século XX, com o surgimento do elogio à mestiçagem, quando ganhava força a busca pelas "raízes da nação" e quando a ação de "mediadores culturais", como Noel Rosa, teria sido de fundamental importância para elevação do samba a "ritmo nacional", suprindo a necessidade de unificação do País (VIANNA 1995: 115).

Seja como forma de resistência, por temor político, pela ação dos "mediadores culturais" ou simplesmente pela atração que os ritmos populares causavam nas classes sociais mais elevadas, elementos culturais das chamadas camadas "populares" passaram para o centro do sistema musical brasileiro. A música, veículo da oralidade dessas camadas, chegava às recém-criadas rádios em um clima de grande efervescência política que culminou com a Revolução de 1930 e incorporou o forte nacionalismo da "Era Vargas".

É nesse contexto que vemos as primeiras canções tocadas no rádio, trazendo as primeiras marcas dos "confrontos linguísticos" na música brasileira. 
Tooge, M. D. B. - Acorde estrangeiro: representação e confrontos linguísticos na música brasileira

\section{A corrente de resistência e a utopia da mestiçagem}

Músicos da década de 1930 já criavam, assim, canções de forte cunho humorístico ${ }^{2}$, típicas do clima que invadia os programas de rádio brasileiros, para rebater a influência estrangeira.

Como conta Ramiro Lopes BICCA J UNIOR (2001), se a França foi "o primeiro modelo de sociedade para a elite brasileira (...) a influência americana, na realidade, refletia-se mais nas expressões idiomáticas da população brasileira" (BICCA J UNIOR 2000: 1). Entretanto, as canções populares revelavam mais do que isso: elas transmitiam as narrativas orais de uma população que vivia na tensão do nacionalismo em uma época de questionamentos constantes sobre sua identidade. Em função disso, as línguas passaram a ser instrumentos de artistas para realizar tal embate ideológico da nacionalidade.

O "fox-nonsense", ou "soneto-piada", conforme definição de SALIBA (2002: 280), Canção para inglês ver, de LAMARTINE BABO (1931), mostrava que a ordem era ironizar. Babo criara uma paródia onde, através da homofonia, desmistificava o uso do idioma inglês, transformando-o em "galhofa" (SALIBA 2002: 282) ${ }^{3}$. Os sons que imitam o idioma inglês na canção misturam-se a termos de origem indígenas como "itapiru" ou "jaceguai", ou ainda como 0 nome tipicamente português "Silva Manoel", e o tom "elevado" do idioma

\footnotetext{
${ }^{2}$ Elias Thomé Saliba, em Raízes do Riso (SALIBA: 2002) afirma que "quando o rádio procura uma linguagem própria, rápida, concisa e colada no dia-a-dia, suscetível de registrar 0 efêmero do cotidiano, ele vai encontrar aquilo que as criações humorísticas já haviam de certa forma elaborado em estreita ligação com o teatro musicado, o teatro de revista, as primeiras gravações fonográficas, e até mesmo as primeiras produções cinematográficas: a mistura linguística, a incorporação anárquica de ditos e refrãos conhecidos por ampla maioria da população, a concisão, a rapidez, a habilidade dos trocadilhos e jogos de palavras, a facilidade na criação de versos prontamente adaptáveis à música, aos ritmos rápidos da dança e aos anúncios publicitários" (SALIBA 2002: 228).

${ }^{3}$ As inúmeras referências e chaves de época são analisadas mais profundamente por SALIBA (2002: 280-283).
} 
Tooge, M. D. B. - Acorde estrangeiro: representação e confrontos linguísticos na música brasileira

estrangeiro é rechaçado, através de referências banais de nosso cotidiano, como "salada de alface", "abacaxi" e "sanduíche". Tais referências não são ingênuas ou aleatórias, mas históricas e pontuais, "delatando" acontecimentos da época, como a instalação da companhia Shell ou da Standard Oil no Brasil:

I love you / Forget sclaine / Maine Itapirú / Morguett five underwood / I shell / no bond Silva Manoel / Manoel... Manoel... I love you To have steven via-Catumby / Independence lá do Paraguay / Studbaker... J aceguay / Yes my glass (bis) / Salada de alface (bis) / Fly Tox my till.. / Standard oil... / Forget not me / Oi!

Contrário ao "estrangeirismo", Assis Valente, em 1932, lançou "Tem francesa no morro", para "destronar" o idioma francês. Sua "petite francesa" acaba dançando samba "em cime de mesa":

Donê muá si vu plé lonér de dancê aveque muá / Dance loiô / Dance laiá / Si vu frequenté macumbe entrê na virada e fini por samba / Dance loî̂ / Dance laiá / Vian / Petite / francesa / Dancê le classique / Em cime de mesa (...)

Já sua crítica ao uso do idioma inglês é apresentada na canção Good-bye boy, também de 1932, onde Valente fez uso de empréstimos da língua estrangeira para criticar o "moreno frajola que nunca frequentou as aulas da escola" por ter "mania de inglês". Mais ainda, sua crítica se vira contra a própria instauração da companhia canadense "Light" como monopolizadora da distribuição de energia elétrica local. Mas, a grande ironia foi a canção tornar-se popular justamente na voz da futura "embaixadora da Boa Vizinhança" do Brasil nos Estados Unidos, Carmen Miranda:

Good-bye, good-bye boy, deixa a mania do inglês / É tão feio p'rá você, moreno frajola que nunca frequentou as aulas da escola (...) Não é mais boa noite, nem bom dia / Só se fala "good-morning, good-night" 
Tooge, M. D. B. - Acorde estrangeiro: representação e confrontos linguísticos na música brasileira

I Já se desprezou o lampião de querosene / Lá no morro só se usa a luz da Light (oh, yes!)

O discurso de resistência à influência estrangeira, resultante da reviravolta identitária modernista, se cristalizaria em 1933 na canção "Não tem Tradução" de Noel Rosa, onde o "poeta da Vila" afirmaria que:

O cinema falado é o grande culpado da transformação / Dessa gente que sente que um barracão prende mais que o xadrez / Lá no morro, seu eu fizer uma falseta / A Risoleta desiste logo do francês e do Inglês / (...) Essa gente hoje em dia que tem a mania da exibição / Não entende que o samba não tem tradução no idioma francês / Tudo aquilo que o malandro pronuncia / Com voz macia é brasileiro, já passou de português (...) (NOEL ROSA 1933).

Essa corrente de crítica ao estrangeirismo na música brasileira não morreu nos anos 1930. Ainda nas últimas décadas, surgiram canções como 0 Samba do Approach de ZeCA BALeIRo (1999), onde vigora a crítica ao "exagero" do uso de termos estrangeiros no Brasil ${ }^{4}$.

\section{Entrega e sedução}

Mas, as décadas seguintes trariam novidades para a música brasileira. Com a política da Boa Vizinhança, Carmen Miranda seria "exportada" para os Estados Unidos e se tornaria "the Brazilian Bombshell". Através de Carmen, 0 português seria cantado pela primeira vez em filmes de Hollywood. Em 1938, 0 ator americano Tyrone Power, em visita ao Brasil, já afirmava: "Não é preciso entender o que ela canta. Não é preciso saber o português para entender o samba, cantado por ela com tanta expressão, tanto bulício, tanto encanto nas suas canções que não há quem não fique cativo" (in MENDonçA

\footnotetext{
${ }^{4}$ Uma canção mais agressiva chamada Estrangeirismo, de Carlos Silva e Sandra Regina, também faz crítica acirrada à americanização no Brasil, tentando reproduzir um linguajar "regional".
} 
Tooge, M. D. B. - Acorde estrangeiro: representação e confrontos linguísticos na música brasileira

1999: 15). Então, para quê cantar? Porque não apenas dançar? Carmen cantava porque os sons que emitia representavam algo, ainda que não o que ela imaginava: o "bulício", o "encanto", a "sedução". Carmen cantava em português, em inglês ou usando a "inversão de código", ou seja, inserindo o português no meio de uma canção em inglês. 0 idioma lusófono "emergia", como quem sobe à tona na tentativa desesperada de não se afogar, para não fenecer. É o caso de "I'm just wild about Harry", canção cantada por Carmen no filme Greenwich Village (Serenata Boêmia) de 1944. Ainda que a escolha da introdução da língua portuguesa não fosse sua, e provavelmente estivesse ali como mais um elemento de exotismo, através dela Carmen levava para o "Tio Sam" aquilo que imaginava ser a "verdadeira cultura brasileira":

Oh, I'm just wild about Harry / And Harry's wild about me / The heavenly blisses of these kisses / It fills me with ecstasy / (...) Hey! I'm just wild about / Samba, batucada, carnaval e café / Por macumba, viramundo e uma figa de Guiné / And Harry's wild about / Ser uma baiana com sandália no pé / $\mathbf{E}$ provar um vatapá com um pouco de acarajé / The heavenly blisses of his kisses / It fills me with ecstasy / Se gosta de baiana é pra mim de colher (...)

Os elementos referentes ao elogio à mestiçagem, ideal que crescia desde o princípio do século XX e se consolidava na obra Casa Grande e Senzala, de Gilberto FreYre (1933), marcavam a fala de Carmen Miranda nessa canção (e em outras).

Em trabalho anterior (TOOGE 2009: 97) demonstrou-se que a imagem sedutora de Carmen Miranda, ícone que mais fortemente incorporou as características de sensualidade, exotismo e de "paraíso tropical" encapsuladas no mito fundador da identidade nacional brasileira (CHAUI 2000), reproduziu-se constantemente, influenciando a recepção de uma forte sucessora, a heroína "Gabriela" de J orge Amado, nos Estados Unidos em 1962. Criada a aura de sedução em torno dos filmes hollywoodianos, a imagem do Brasil ficaria, por muitos anos, vinculada à imagem exótica de Carmen. 
Tooge, M. D. B. - Acorde estrangeiro: representação e confrontos linguísticos na música brasileira

\section{A utopia desenvolvimentista}

Ary Barroso, compositor/parceiro de Carmen, criou em 1939 sua "Aquarela do Brasil", a canção de elogio à pátria e às belezas da nação, que se tornaria o marco da criação do gênero "samba exaltação". A canção traz as marcas da ideologia da época, com o elogio ao "mulato inzoneiro", cantado nos versos de Barroso. A terra de "samba e pandeiro" de Ary Barroso é também a "terra de nosso Senhor", imitando o ditado popular "Deus é brasileiro". Ary Barroso também viajou aos Estados Unidos, e sua "Aquarela do Brasil" foi tornada um "hino-nacional brasileiro" no exterior (FREIREMedeIRos 2005: 21), principalmente após ter sido tema do filme Saludo Amigos, de Walt Disney, em 1942. Mas, a canção só ganhou letra no idioma inglês em 1957, quando Bob Russel escreveu a letra de "Brazil". Nela, as menções à mestiçagem ou às origens africanas, como em "mulato inzoneiro", "mãe preta" ou "rei congo", marcas do caráter ufanista da canção, desaparecem totalmente e o tom da canção se aproxima da nova linha romântica de sucessos brasileiros nos Estados Unidos: a Bossa Nova.

\footnotetext{
"Brazil / The Brazil that I knew / Where I wandered with you / Lives in my imagination. / Where the songs are passionate, / And a smile has flash in it, / And a kiss has art in it, / For you put your heart in it, I And so I dream of old Brazil / Where hearts were entertaining J une, / We stood beneath an amber moon / And softly murmured "someday soon" / We kissed and clung together, / Then tomorrow was another day / The morning found me miles away / With still a million things to say / Now when twilight dims the sky above, / Recalling thrills of our love, / There's one thing I'm certain of; / Return I will / To old Brazil."
}

No Brasil, músicos, artistas e público da Bossa Nova "respiraram" o 
Tooge, M. D. B. - Acorde estrangeiro: representação e confrontos linguísticos na música brasileira

"oxigênio mental" ${ }^{5}$ da política desenvolvimentista do governo Juscelino Kubitschek, cuja obra musical mais representativa talvez seja a "Sinfonia da Alvorada", encomendada pelo presidente a Antônio Carlos J obim e Vinicius de Moraes em 1958. Nas palavras de Adriana Evaristo Borges:

\begin{abstract}
A princípio (...) a música bossa nova não tinha a intenção de transformar-se em objeto político, mas essa aproximação aconteceu em função de uma concordância de intenções dos produtores da bossa nova e o projeto político de J $\mathrm{K}$, onde o urbano servia como referencial de modernidade. $E$, nesse aspecto, naquela conjuntura música e política parecem ter cumprido seu papel (BORGES 2007: 1).
\end{abstract}

Os Estados Unidos ouviram muitas das canções da Bossa Nova também na voz de Sinatra. Foi paradigmático seu dueto "bilíngue" com Tom Jobim cantando a "Garota de Ipanema", agora "Girl from Ipanema" (1963), alternando versos da letra em inglês de Norman Gilbel com os da canção em português. Segundo Charles A. Perrone (2002: 17), o sucesso da canção [nos Estados Unidos] foi maior do que 0 alcançado por qualquer canção estrangeira. Novamente temos a imagem da mulher sensual, alegre, divertida e sedutora: "Tall and tan and young and lovely" é a garota brasileira que caminha em direção ao mar de Ipanema, sem olhar para seu pobre apaixonado.

Várias outras canções brasileiras de Bossa Nova ganharam versões em inglês, entre elas "O Barquinho", "Desafinado", "Samba de uma nota só", "Corcovado" e "Chega de Saudades". Estavam entre os "letristas" Gene Lees, Arto Lindsay, Norman Gimbel e o próprio Tom Jobim. A Bossa Nova deixou também vários "herdeiros", sendo Bebel Gilberto, filha de J oão Gilberto, uma das cantoras de maior sucesso nos Estados Unidos. Entretanto, o fato mais interessante da Bossa Nova foi a canção "Mais que nada" (1963), que "alcançou na interpretação de Sérgio Mendes, o topo da lista das canções

\footnotetext{
${ }^{5}$ A expressão "oxigênio mental" foi cunhada pelo Prof. Dr. Elias Thomé Saliba em sua obra Raízes do Riso (2002: 302).
} 
Tooge, M. D. B. - Acorde estrangeiro: representação e confrontos linguísticos na música brasileira

mais tocadas nos Estados Unidos de acordo com o ranking da BillBoard" (CHaves 2010: 2) ${ }^{6}$ sem nunca ter sido traduzida para 0 inglês. 0 fato demonstra mais uma vez que os "sentidos" passados pelo ritmo e pelo "clima" gerado pelas canções se sobrepunham à curiosidade do público quanto ao significado das palavras, do "idioma" cantado. Em uma pesquisa piloto do governo brasileiro, realizada em 2005, quando os entrevistados foram perguntados se o idioma era ou não uma barreira para a divulgação da música brasileira no exterior, 66,6\% dos entrevistados responderam que "não". Segundo a pesquisa, apesar do grande número de entrevistados [serem] falantes de português, "(...) as respostas (...) referem-se ao senso comum, corroborando a impressão de que o público de música brasileira e 0 estrangeiro têm a expectativa de ouvir os artistas cantarem em sua língua materna, ainda que não compreendam o significado das letras" ${ }^{7}$. Essa barreira a uma maior compreensão da cultura e da língua através da "palavra cantada" teria, entretanto, novos inimigos, que nasceriam do próximo movimento musical de nossa história: a Tropicália.

\section{Tropicália e a utopia antropofágica}

Que a música popular centralizasse as energias (...) só reafirma a força de uma tradição que possibilitou a bossa nova: a música popular brasileira tem sido, de fato, para nós como para estrangeiros, o som do Brasil do descobrimento sonhado. (...) Ela é a mais eficiente arma de afirmação da língua portuguesa no mundo, tantos insuspeitados amantes esta tem conquistado por meio da magia sonora da palavra cantada à moda brasileira, tantos insuspeitados amantes esta tem conquistado por meio da magia sonora da palavra cantada à moda brasileira.

Caetano Veloso

\footnotetext{
${ }^{6}$ A canção esteve várias vezes entre as dez mais tocada da revista Billboard, desde seu lançamento em 1967.

${ }^{7}$ Estes dados foram gentilmente fornecidos pelo músico responsável pela pesquisa piloto, Felipe Radicetti.
} 
Tooge, M. D. B. - Acorde estrangeiro: representação e confrontos linguísticos na música brasileira

A década de 1960 também foi marcada por diferentes formas de nacionalismo, agora muito vinculadas à tensão política que resultou no golpe militar de 1964 e se expandiu com ele. Enquanto a Jovem Guarda, muito influenciada pelo rock americano, ganhava numerosos fãs no Brasil e juntavase à Bossa Nova na aceitação dos modelos externos, uma corrente de resistência representada principalmente pelo movimento estudantil também se fortalecia. Se a Guerra Fria fizera crescer a influência comunista na política brasileira, com a derrota para os militares, o nacionalismo de esquerda se tornara mais agudo e era pesada a crítica contra aqueles "coniventes com o imperialismo norte-americano". Vivia-se o momento das canções engajadas, que precisavam driblar a rígida censura da ditadura. Já os militares incentivavam o nacionalismo "patriótico", também rejeitando a influência externa.

Em meio a tais pressões no meio artístico, os membros da futura Tropicália se rebelavam, paradoxalmente "decretando" ser "proibido proibir". Seu ideal: "retomar a linha evolutiva da música brasileira" ${ }^{8}$. Nas palavras de Caetano Veloso:

De fato, nós tínhamos percebido que, para fazer o que acreditávamos que era necessário, tínhamos nós que livrar do Brasil tal como 0 conhecíamos. Tínhamos que destruir o Brasil dos nacionalistas, tínhamos que ir mais fundo e pulverizar a imagem do Brasil carioca (VELOSO 1997: 46).

Assumindo um caráter antixenofóbico, os Tropicalistas se autodenominaram neoantropofágicos e, sofrendo a influência dos poetas concretistas Augusto e Haroldo de Campos, buscaram unir tradição e modernidade, primitivo e tecnológico, nacional e estrangeiro. A linguagem dos Tropicalistas, à maneira oswaldiana, era telegráfica, privilegiando a

\footnotetext{
${ }^{8}$ Para o conceito de "linha evolutiva" ver: NAPOLITANo (2007: 95-108).
} 
Tooge, M. D. B. - Acorde estrangeiro: representação e confrontos linguísticos na música brasileira

hibridação lexical.

É, no entanto, a partir do exílio de Caetano e Gil, que a relação com o estrangeiro mais aparece nas canções dos dois artistas, em especial nas de Caetano. Seu álbum Transa, lançado em 1972, praticamente um álbum de exílio, traz aquela que parece ser a primeira canção do compositor direcionada ao estrangeiro: "You don't know me". A canção, escrita originalmente em língua inglesa, fala do desconhecimento do "outro", da barreira que impossibilita a troca, e chega ao refrão com uma quebra tanto no ritmo quanto na linguagem: a intertextualidade se une à técnica da alternância de códigos, e ambas são utilizadas para inserir a "identidade" do interlocutor: a história de escravidão surge nas palavras "devoradas" da canção "Maria Moita" de Carlos Lyra, enquanto a religiosidade surge nos versos de "Reza" de Edu Lobo. A marca de seu próprio "Saudosismo" aparece nas rimas de sua canção homônima:

\begin{abstract}
You don't know me / Bet you'll never get to know me / You don't know me at all / Feel so lonely / The world is spinning round slowly / There's nothing you can show me / From behind the wall / Show me from behind the wall / Show me from behind the wall / Show me from behind the wall / Nasci lá na Bahia de mucama com feitor / 0 meu pai dormia em cama, minha mãe no pisador / Laia ladaia sabadana ave maria / Laia ladaia sabadana ave maria / Eu você nós dois, já temos um passado meu amor / Um violão guardado, aquela flor (...)
\end{abstract}

A técnica de inserir o português estrategicamente nos refrãos das canções, buscando seduzir o ouvinte a cantar no idioma português, assim como a tentativa de inserir elementos da cultura de origem do compositor na canção elaborada em idioma estrangeiro parece ter ecoado entre vários artistas brasileiros que se apresentam fora do Brasil. Representar de forma "missionária" sua "nação", através da tentativa de "transmitir elementos culturais", ou seja, promover a "transculturação": essa também parece ser a ideia que origina canções como as do grupo "Forró in the Dark", conj unto cujo 
Tooge, M. D. B. - Acorde estrangeiro: representação e confrontos linguísticos na música brasileira

nome por si só já revela a vontade de "misturar" ou "hibridizar" ritmos, línguas, canções, culturas. Gravada na voz de David Byrne, o sucesso de Luiz Gonzaga e Humberto Teixeira, "Asa Branca", leva o drama do migrante que foge da cruel ação da natureza, da seca nordestina, deixando lá o amor e a promessa de regresso. A versão do "Forró in the Dark" apresenta uma tentativa forte de manutenção de elementos culturais brasileiros, com a menção à festa de São J oão mantida no português, a exclamação "adeus Rosinha" intercalada com versos em inglês e a mesma estratégia de trazer no refrão a inversão de códigos:

\begin{tabular}{|c|c|}
\hline $\begin{array}{l}\text { ASA BRANCA (Luiz Gonzaga / } \\
\text { Humberto Teixeira) }\end{array}$ & $\begin{array}{l}\text { ASA BRANCA (Forró in the Dark - } \\
\text { David Byrne) }\end{array}$ \\
\hline Quando oiei a terra ardendo & When I heard the land was burning \\
\hline Qual a fogueira de São J oão & Like the bonfires of São J oão \\
\hline Eu preguntei a Deus do céu, ai & I asked God up there in his heaven \\
\hline Por que tamanha judiação & What is happening to us now? \\
\hline Que braseiro, que "fornaia" & What a hellfire, what a furnace \\
\hline Nem um pé de “prantação” & Not a tree was left alive \\
\hline Por farta d'água perdi meu gado & And all my cattle, they laid there dying \\
\hline Morreu de sede meu alazão (...) & And even my horse steed did not survive \\
\hline Inté mesmo a asa branca & And the white wing dove \\
\hline Bateu asas do sertão & has flown now, far away from this backland \\
\hline "Intonce" eu disse adeus Rosinha & So I say now, "adeus Rosinha" \\
\hline Guarda contigo meu coração & Know in your heart, I'll be back again \\
\hline "Intonce" eu disse adeus Rosinha & "Intonce" eu disse adeus Rosinha \\
\hline Guarda contigo meu coração (...) & Guarda contigo meu coração (...) \\
\hline
\end{tabular}

Na versão inglesa de Asa Branca, a voz do sertanejo aflora e se mostra, 
Tooge, M. D. B. - Acorde estrangeiro: representação e confrontos linguísticos na música brasileira

reunindo-se novamente ao ritmo ao qual pertence e cujo espaço houvera cedido. Exílio, fuga de um ambiente hostil e melancolia do regresso são temas que certamente trazem um apelo ao público internacional, já que as guerras e as disputas de terra, os diversos "exílios" e "diásporas" trazem consigo a mesma carga nostálgica. Tais características não passaram despercebidas ao produtor David Byrne.

\section{Conclusão}

Os processos de busca de representação, construção identitária e "confrontos linguísticos" aqui descritos certamente não se esgotam aí, mas o que foi apresentado serve como base para compreender as diversas tentativas de representação da cultura brasileira vinculadas a diferentes "nacionalismos" na música brasileira. Em algumas delas, a hibridação, assim como os processos de representação e de transculturação foram mais marcantes. Mas, todas refletiram as ansiedades sociais resultantes dos acontecimentos históricos dos últimos séculos.

Diferentes grupos de artistas, "mediadores culturais" ou "representantes" debateram-se, e ainda se debatem, entre sua inserção no mercado mundial e a valorização da cultura brasileira, enfrentando a ansiedade de transmitir uma identidade "desejada", ou "imaginada" e a "imagem congelada" pelo mito fundador. Nessa constante busca de reelaboração da "identidade brasileira", a "palavra cantada" transformou-se em um novo instrumento para desconstruir as imagens monolíticas e congeladas da "nação brasileira". 
Tooge, M. D. B. - Acorde estrangeiro: representação e confrontos linguísticos na música brasileira

\section{Referências bibliográficas}

AnDRADE, O. Manifesto antropófago. In Obras Completas. A Utopia

Antropofágica. São Paulo, Globo, 1995.

ANDERSON, B. Imagined commuinities: reflections on the origin and spread of capitalism. Londres/ Nova lorque, Verso, 1991.

BethelL, L. O Brasil e a ideia de "América Latina" em perspectiva histórica. Estud. hist. (Rio J.), Rio de Janeiro, v. 22, n. 44, 2009.

BICCA J UNIOR, R. L. Coisas nossas: a sociedade brasileira nos sambas de Noel Rosa. - Faculdade de Letras, Porto Alegre, PUCRS, 2001.

BhABHA, H. "DissemiNação: o tempo, a narrativa e as margens da nação moderna" In: O local da cultura. Editora UFMG, 2001.

BORGES, A. E. República bossa nova: o encontro entre a música e a política (1956-1960). Revista Espaço Acadêmico, No. 76 - Set 2007. Disponível em http:// www. espacoacademico.com.br/ 076/ 76borges. htm> . Acesso em 05/ 08/ 2011.

Bresser-PereiRA, L. C. Nacionalismo no centro e na periferia do capitalismo, In: Revista Estudos Avançados 22 (62). São Paulo, USP, 2008.

CASTRO, R. Carmen: uma biografia. São Paulo: Companhia das Letras, 2005.

CHAuí, M. Brasil, mito fundador e sociedade autoritária. São Paulo, Fundação Perseu Abramo, São Paulo, 2000.

CHAVES, R. P. "País Tropical e seu mimetismo: o discurso ufanista associado a Wilson Simonal e a desinvenção Tropicalista" in Revista de Ciências Humanas, Florianópolis, EDUFSC, v. 44, n. 2, p. 293-311, 2010.

ConCEIÇÃo, R. I. S. "A língua Portuguesa no Brasil: a construção de um semióforo". In: Anais I SIMELP - Simpósio Mundial de Estudos de Língua Portuguesa FFLCH/ USP, 2008.

Freire-Medeiros, B. O Rio de J aneiro que Hollywood Inventou. Rio de J aneiro, J orge Zahar, 2005.

FreYre, G. Casa Grande \& Senzala. Rio de J aneiro, Maia \& Schmidt - 1933.

HALL, S. A identidade cultural na pós-modernidade. DP\&A Editora, Rio de J aneiro, 2006.

HobSBAwm, E. J. Nations and Nationalism Since 1780. Cambridge, Cambridge University Press, 1990. 
Tooge, M. D. B. - Acorde estrangeiro: representação e confrontos linguísticos na música brasileira

MendonçA, A. R. Carmen Miranda foi a Washington, Rio de J aneiro/ São Paulo, Record, 1999.

Napolitano, M.; Wasserman, M. C. Desde que o samba é samba: a questão das origens no debate historiográfico sobre a música popular brasileira. Rev. bras. Hist., São Paulo, v. 20, n. 39, 2000.

Nicolau NetTo, M. Música brasileira e identidade nacional na mundialização, São Paulo: Annablume; Fapesp, 2009.

SAID, E. Culture and Imperialism. Edward W. Said. New York: Alfred A. Knopf, 1993.

SAntos, L. A. C. O pensamento sanitarista na Primeira República: Uma ideologia de construção da nacionalidade. In: Revista de Ciências Sociais, Rio de J aneiro, v. 28, n. 2, p.193-210, 1985.

Yмосzко, M. Enlarging Western Translation Theory: Integrating on-Western Thought about Translation SOAS, 2003.

- "Reconceptualizing Translation Theory. Integrating Non-Western Thought about Translation". In: Translating Others, Vol. 1. Manchester: St. J erome Publishing, 2006, 13-32.

TotA, A. P. O imperialismo sedutor. Cia. das Letras, São Paulo, 1999.

Veloso, C. Verdade Tropical. Companhia das Letras, São Paulo, 1997.

"Carmen Miranda Dada" The New York Times, 1991 \& Folha de S. Paulo, 22/ 10/ 1991.

VIANNA, H. O mistério do samba. Rio de J aneiro: Zahar/UFRJ , 1995. 